\title{
Prospective evaluation of blood concentration of mitochondrial DNA as a marker of toxicity in 157 consecutively recruited untreated or HAART-treated HIV-positive patients
}

\author{
Franck Chiappini ${ }^{1,4}$, Elina Teicher ${ }^{2}$, Raphaël Saffroy ${ }^{1}$, Patrick Pham ${ }^{1}$, Bruno Falissard ${ }^{3}$, \\ Alain Barrier ${ }^{5}$, Stephan Chevalier ${ }^{4}$, Brigitte Debuire ${ }^{1}$, Daniel Vittecoq ${ }^{2}$ and \\ Antoinette Lemoine ${ }^{1}$ \\ ${ }^{1}$ Service de Biochimie et de Biologie Moléculaire - INSERM 602; ${ }^{2}$ Service d'Infectiologie; ${ }^{3}$ Service de Santé \\ Publique Hôpital Paul Brousse, Faculté de Médecine Paris-Sud, Université Paris XI, Villejuif Cedex, France; \\ ${ }^{4}$ PFIZER, Centre de Recherche, Amboise, France and ${ }^{5}$ INSERM 444, Hôpital St Antoine, Paris, France
}

\begin{abstract}
Highly active antiretroviral therapy (HAART) can cause mitochondrial toxicity. The concentration of mitochondrial DNA (mtDNA) in peripheral blood cells has been reported to be a marker of this toxicity. However, these observations are controversial and were drawn from small series. Thus, we analysed the value of blood mtDNA as a marker of mitochondrial toxicity in a large cohort of human immunodeficiency virus (HIV)infected out-patients during routine clinical evaluations. Real-time quantitative PCR was used to determine the mtDNA to nuclear DNA (nDNA) ratio in peripheral blood mononuclear cells from 157 consecutive HIV-1-infected patients (13 naive, 144 receiving HAART) and 30 HIV-1-uninfected patients. The mtDNA to nDNA ratio was significantly lower in both groups of HIV-infected patients than in the control group. No significant difference was observed between treated and naive HIV-infected patients. Lactataemia was significantly lower in controls than in the group of HIV-treated patients. None of the treated patients had lactataemia $>5 \mathrm{mmol} / \mathrm{l}$ or bicarbonates $<20 \mathrm{mmol} / \mathrm{l}$. Triglyceride levels were significantly higher in the HAART-treated patients than in the nontreated patients. Clinical symptoms of lipodystrophy were observed in 62 HAART-treated patients. These symptoms were not associated with an abnormal mtDNA to nDNA ratio or plasma triglyceride concentration. The mtDNA to nDNA ratio was lower in DDI/D4T-treated patients than in AZT/3TC-treated patients. In conclusion, there are no obvious links between the mtDNA to nDNA ratio in peripheral mononuclear cells and any clinical symptoms or lactate level. Thus, the mtDNA to nDNA ratio in leukocytes does not seem to be an accurate marker of mild and/or long-term mitochondrial toxicity.
\end{abstract}

Laboratory Investigation (2004) 84, 908-914, advance online publication, 3 May 2004; doi:10.1038/labinvest.3700113

Keywords: HAART toxicity; HIV infection; lactataemia: lipodystrophy; mitochondrial DNA; mitochondrial toxicity

Highly active antiretroviral therapy (HAART) has substantially reduced morbidity and mortality due to HIV-1 (human immunodeficiency virus type 1). However, long-term treatment with these drugs is sometimes associated with adverse effects, especially the development of lipodystrophy syndrome and hyperlipidaemia. Both of these side effects appear to be linked to the use of HIV protease

Correspondence: A Lemoine, Service de Biochimie et de Biologie Moléculaire - INSERM 602, Hôpital Paul Brousse, 12 avenue Paul Vaillant-Couturier, 94800 Villejuif, France.

E-mail: antoinette.lemoine@pbr.ap-hop-paris.fr

Received 17 December 2003; revised 16 February 2004; accepted 17 February 2004; published online 3 May 2004 inhibitors. ${ }^{1-4}$ However, the broad spectrum of toxicities associated with nucleoside analogue reverse transcriptase inhibitors (NRTIs), which result in mitochondrial dysfunction, suggests that NRTIs can also cause lipodystrophy syndrome. ${ }^{5}$

Mitochondrial toxicity is related to the inhibition of DNA polymerase- $\gamma$, an essential enzyme for the replication of mitochondrial DNA (mtDNA), by NRTIs. This is at least partly responsible for the adverse effects of NRTIs, which include lactic acidosis, hepatic steatosis, myopathy, cardiomyopathy, peripheral neuropathy, pancreatitis and possibly the lipodystrophy syndrome ${ }^{6-9}$ The clinical toxicity has been attributed to mtDNA depletion associated with mitochondrial dysfunction that 
affects the respiratory chain and fatty acid beta oxidation. Mitochondrial alterations induce the release of lactates into the bloodstream.

The most dramatic presentation of mitochondrial toxicity is the development of acute lactic acidosis, which is fatal in most cases. ${ }^{10,11}$ Prolonged high blood lactate concentrations are associated with a poor prognosis. ${ }^{12,13}$ Venous blood lactate concentrations have been used to monitor for mitochondrial damage, but the clinical value of this method remains unclear. This method is not ideal because it is not specific and because it is subject to technical and physiological variability. ${ }^{14,15}$ Moreover, severe mitochondrial defects may coexist in one specific organ with normal lactate levels in the blood. ${ }^{16}$ The concentration of lactate in the blood may also increase as a result of decreased clearance in the liver due to the presence of steatosis rather than due to increased lactate production. ${ }^{17}$ The gold standard would be a liver or a muscle biospy to evaluate the level of mitochondrial toxicity (liver steatosis or steatohepatitis), notably in $\mathrm{HIV} / \mathrm{HCV}$ (hepatitis C virus) coinfected patients. However, biopsy is not practical for routine monitoring.

The depletion of mtDNA was recently reported to be an early and direct marker of NRTI toxicity. ${ }^{18}$ It is possible that the quantification of mtDNA in peripheral blood cells could be a more sensitive and earlier indicator of the mitochondrial toxicity of drugs than cell viability. ${ }^{19,20}$ However, other studies gave controversial results. ${ }^{21,22}$ All of these studies were performed on small series of patients. We assessed the long-term toxicity of HAART in 157 consecutive out-patients who had been receiving HAART for a mean period of 66 months, to determine whether the mtDNA to nuclear DNA (nDNA) ratio in peripheral blood mononuclear cells can be used to screen for mitochondrial toxicity in routine practice.

\section{Materials and methods}

\section{Patients}

All the HIV patients aged between 20 and 50 years who attended the Infectiology Department of Paul Brousse Hospital (Villejuif, France) as an out-patient between May 3rd and 28th 2002 were included in this study, regardless of whether they were treated by HAART. In all, 13 asymptomatic HIV patients had never been treated with antiretroviral drugs (two females and 11 males) and 144 HIV patients had been continuously treated with antiretroviral drugs for between 1 and 168 months (mean $=66.3$ months). All 144 patients had received AZT (zidovudine) and 3TC (lamivudine) and some were switched to ABC (abacavir), TDF (tenofovir), and the others to DDI (didanosine) and/or D4 T (stavudine). A control group of $30 \mathrm{HIV-1-negative} \mathrm{patients} \mathrm{was} \mathrm{also} \mathrm{ana-}$ lysed. The patients gave a blood sample after a 3-h period of rest. All patients gave informed consent for inclusion, according to the rules at our institution.

Age, sex, CD4 count, HIV-1 viral load, and nature and duration of treatments with HAART were recorded at the time of inclusion (Table 1).

Blood samples taken during out-patient visits after $12 \mathrm{~h}$-overnight fast period. Moreover, all the patients had a 3-h period of rest before subjecting to routine tests including lactates, creatine phosphokinase, amylase, triglyceride and cholesterol. We also collected a 7-ml venous blood sample on EDTA for peripheral blood mononuclear cells (PBMC) isolation and DNA preparation.

\section{Biochemical Data}

Venous blood collected in sodium-fluoride-potassium oxalate tubes and stored in ice until analysis was used to measure fasting blood lactate in resting patients. Cholesterol, triglycerides, HDL cholesterol, amylase, creatine phosphokinase, and bicarbonates in blood according to routine procedures using a Synchron LX20 Clinical System (Beckman Coulter, Villepinte, France).

\section{DNA Extraction}

After lysing red blood cells in Tris-HCl $(20 \mathrm{mmol} / \mathrm{l})$ and EDTA (5 mmol/l) buffer (Sigma, L'Isle D'Abeau Chesnes, France), total DNA was isolated from PBMC with a Wizard Genomic DNA purification Kit (Promega, Charbonnières, France). Total DNA was stored at $-80^{\circ} \mathrm{C}$.

Table 1 Age, sex ratio, duration of treatment, CD4 count, HIV-RNA load and duration of HIV-seropositivity for each group of patients

\begin{tabular}{|c|c|c|c|c|c|c|c|}
\hline $\begin{array}{l}\text { Group of } \\
\text { patients }\end{array}$ & $\mathrm{N}=$ & $\begin{array}{c}\text { Sex } \\
\text { ratio }(F / M)\end{array}$ & $\begin{array}{c}\text { Age } \\
\text { (mean } \pm \text { s.d. } \\
\text { years) }\end{array}$ & $\begin{array}{l}\text { Duration of } \\
\text { treatment (mean } \pm \\
\text { s.d. months) }\end{array}$ & $\begin{array}{l}\text { CD4-count (mean } \pm \\
\text { s.d. number giga/l) }\end{array}$ & $\begin{array}{c}H I V R N A \\
\text { (mean } \pm \text { s.d. } \\
\text { log copy) }\end{array}$ & $\begin{array}{c}\text { Duration of HIV- } \\
\text { seropositivity } \\
\text { (mean } \pm \text { s.d. months) }\end{array}$ \\
\hline $\begin{array}{l}\text { Control (HIV } \\
\text { negative) }\end{array}$ & 30 & $9 / 21$ & $37.4 \pm 9.2$ & - & - & - & - \\
\hline $\begin{array}{l}\text { Untreated } \\
\text { HIV patients }\end{array}$ & 13 & $2 / 11$ & $36.0 \pm 3.7$ & - & $0.484 \pm 0.159$ & $3.71 \pm 1.22$ & $\begin{array}{c}69.1 \pm 72.0 \\
{[0.4-180]}\end{array}$ \\
\hline $\begin{array}{l}\text { Treated } \\
\text { HIV patients }\end{array}$ & 144 & 29/115 & $40.1 \pm 5.5$ & $66.3 \pm 42.0$ & $0.440 \pm 0.276$ & $2.95 \pm 1.95$ & $\begin{array}{c}118.4 \pm 62.0 * \\
{[1.5-252]}\end{array}$ \\
\hline
\end{tabular}

\footnotetext{
${ }^{*} P=0.06$ compared to the untreated HIV patients.
} 


\section{MtDNA Quantification}

We quantified mtDNA in the total DNA extracted from each patient. For this, we used the method described by Gahan et $a l^{23}$ and modified by Cote et $a{ }^{18}{ }^{18}$ In brief, the nuclear gene ( $\beta$-actin) and the mitochondrial gene (cytochrome $b$ or cyt $b$ ) were quantified separately by real-time quantitative PCR (polymerase chain reaction). We amplified a part of the cyt $b$ mitochondrial gene by use of specific primers, Mito-CytB-F CAACATCTCCGCATGAT GAAA and Mito-CytB-R CCATAATTTACGTCTC GAGTGATGTG and a specific probe 5'-6-FamCCATGCACTACTCACCAGACGCCTCAA-3'-Tamra. The $\beta$-actin gene was amplified by the Taqman $\beta$-Actin ${ }^{\mathbb{R}}$ mix (Roche, Meylan, France). The PCR mixtures contained $7 \mu \mathrm{l}$ of water, $12.5 \mu \mathrm{l}$ of QPCRmastermix ${ }^{\circledR}$ (Eurogentec, Angers, France), $0.4 \mathrm{pmol} / \mu \mathrm{l}$ of each primer and $0.2 \mathrm{pmol} / \mu \mathrm{l}$ of each probe. Each sample was subjected to real-time PCRs in triplicate. The amplification conditions consisted of an enzyme activation of $2 \mathrm{~min}$ at $50^{\circ} \mathrm{C}$, followed by a single denaturation step of $10 \mathrm{~min}$ at $95^{\circ} \mathrm{C}$, and 50 cycles of $15 \mathrm{~s}$ at $95^{\circ} \mathrm{C}$ and $1 \mathrm{~min}$ at $60^{\circ} \mathrm{C}$. Fluorescence was measured at the end of each annealing step. A standard curve of 10, 100, 1000, 10000 and 100000 nuclear-genome equivalents was included in each run, and the same nuclear-genome equivalent values were used to quantify both the nuclear ( $\beta$-actin) and mitochondrial (cyt $b$ ) genes. The data are expressed as the ratio of the mean mitochondrial DNA value of the triplicate measurements to the mean nuclear DNA value ( $\beta$-actin) of the triplicate measurements for a given extract (mtDNA/ $\beta$-actin).

\section{Statistical Analysis}

Results are expressed as means $(\mathrm{m})$ and standard deviations (s.d.). MtDNA to nDNA ratio and concentrations were compared by use of Fisher's test. Means were compared by the Student's $t$-test after normalisation of variables. Correlations were analysed by Pearson's test. Type one error was set at $5 \%$. Data were analysed using the $\mathrm{R}$ software version 1.5.1. ${ }^{24}$

\section{Results}

\section{The Concentration of mtDNA in the Blood of HIV Patients}

Real-time PCR was used to determine the mtDNA to nDNA ratio in mononuclear peripheral cells. The mean value in the HIV-1-negative control group was $0.38 \pm 0.28$ (Figure 1). This value was considered to be $100 \%$. In untreated HIV-1 patients, the mtDNA to nDNA ratio was $63 \%$ of the value in the controls $(0.14 \pm 0.11, P=0.001)$. This ratio was even lower ( $71 \%$ of the control value) in the treated HIV patients $(0.11 \pm 0.09, P=0.003)$. There was no significant difference in the mtDNA to nDNA ratio between the treated and the untreated HIV-1 patients (Figure 1). Because the mean duration of seropositivity was shorter in the HIV-untreated group compared to the treated patients, although not significant, we have analysed the mtDNA to nDNA ratio in 13 treated HIV-1 patients matched for the seropositivity duration to untreated HIV-1 patients. The mean mtDNA to nDNA ratio in the latter patients $(n=13)$ was $0.11 \pm 0.09$. The difference was not significant.

\section{Lactataemia in HIV Patients}

The mean fasting venous blood lactate concentration in the control group was $1.2 \pm 0.43 \mathrm{mmol} / \mathrm{l}$ (range $0.4-2.5 \mathrm{mmol} / \mathrm{l}$ ). This value was similar in the untreated HIV-1 patients $(1.4 \pm 0.8 \mathrm{mmol} / \mathrm{l}$, Figure 2). In the treated patients, the lactate concentration was between 0.5 and $4.0 \mathrm{mmol} / \mathrm{l}$ $(m=1.5 \pm 0.6 \mathrm{mmol} / \mathrm{l})$ and was significantly higher than in controls $(P=0.01)$. None of the treated patients had a lactate concentration of above $5 \mathrm{mmol} / \mathrm{l}$ or acidosis; the lowest bicarbonate concentration was $22 \mathrm{mmol} / \mathrm{l}$. No correlation was found between the mtDNA to nDNA ratio in the peripheral blood mononuclear cells and the fasting venous blood lactate concentration in any of the groups.

\section{Patients with Mitochondrial Toxicity}

Fatigue, muscle weakness, shortness of breath, nausea, vomiting, abdominal pain and peripheral neuropathy were evaluated during the clinical evaluation. None of these signs were associated with a change in the mtDNA to nDNA ratio or lactataemia, may be because they were mostly 'subjective'. Lipodystrophy is considered to be a symptom of long-term toxicity associated with

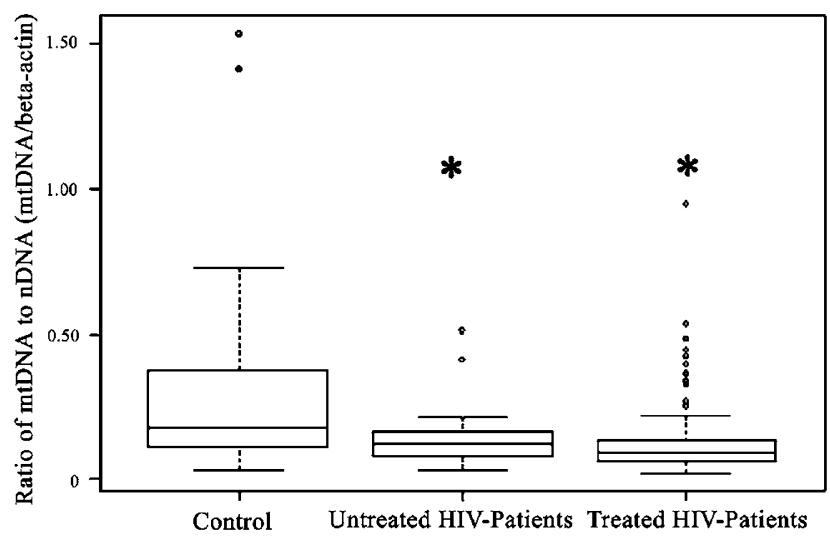

Figure $1 \mathrm{mtDNA}$ to nDNA ratio from PBMC in the different group of patients. *The difference between control and untreated and treated HIV patients is significant. Fisher and Student's test, $P<0.05$. 
protease inhibitors or NRTIs. The features used to assess lipodystrophy were (1) Body mass index, (2) blood parameters and (3) lipodystrophy-specific physical traits (change in central adiposity including breast enlargement, dorsal fat accumulation and increased abdominal girth; evaluation of peripheral lipoatrophic features including decreased fat tissue in the face, buttocks and extremities leading to prominent veins). These data were compared to those independently recorded by the patients in the self-assessment questionnaire. These clinical data led to the establishment of a classification system based on the absence or presence of changes (mild or severe).

None of the HIV-negative patients had change in signs of lipodystrophy, whereas $10 \%$ of the naive HIV patients and $45 \%$ of the HAART-treated patients did $(P<0.001)$. The mean mtDNA to nDNA ratio of the 62 patients who exhibited morphological manifestations of lipodystrophy was $0.16 \pm 0.14$; this

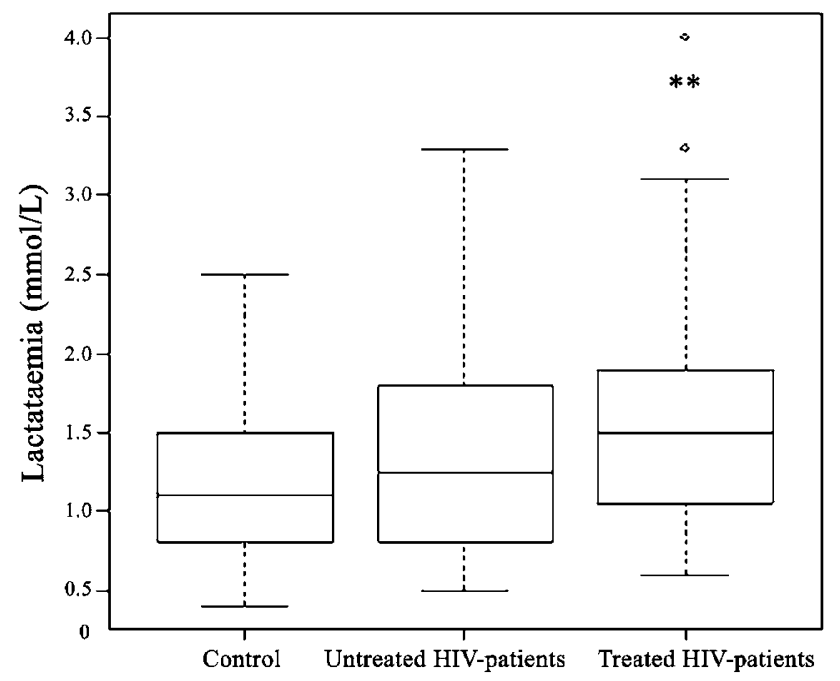

Figure 2 Lactataemia $(\mathrm{mmol} / \mathrm{l})$ in the different group of patients. $* *$ The difference between control and treated HIV patients is signicant. Fisher's and Student's test, $P<0.001$. mean value was not significantly different from that found in the HIV-1-infected patients who did not exhibit signs of lipodystrophy syndrome $(0.13 \pm 0.14)$.

The mean triglyceride level was significantly higher in the HAART-treated patients than in the nontreated patients $(2.4 \pm 1.0$ vs $1.2 \pm 1.7 \mathrm{mmol} / \mathrm{l}$, respectively, $P=0.001$ ). The mean total cholesterol concentration was similar in the HAART-treated patients $(4.8 \pm 1.3 \mathrm{mmol} / \mathrm{l})$ and in the untreated patients $(4.7 \pm 1.4 \mathrm{mmol} / \mathrm{l})$ as well as the mean HDL cholesterol levels (controls: $1.45 \pm 0.36 \mathrm{mmol} / \mathrm{l}$; untreated HIV patients: $1.13 \pm 0.51 \mathrm{mmol} / \mathrm{l}$; treated HIV patients: $1.17 \pm 0.40 \mathrm{mmol} / \mathrm{l}$; no significant differences were observed). No difference was also observed in creatine phospokinase levels $(104 \pm 81$ vs $104 \pm 63 \mathrm{UI} / \mathrm{l})$ or amylasaemia $(67 \pm 33$ vs $82 \pm 31 \mathrm{UI} / \mathrm{l})$ between the treated and nontreated HIV patients, respectively. None of these concentrations were correlated with the mtDNA to nDNA ratio.

\section{Effect of Treatment}

We analysed the mtDNA to nDNA ratio in the HAART-treated patients according to treatment duration and type. All the patients had received AZT and 3TC and then were switched to either ABC/TDF or DDI/D4T. The mtDNA to nDNA ratio was lower in patients receiving DDI/D4T than in patients receiving AZT/3TC $(P<0.05)$. When DDI/ $\mathrm{D} 4 \mathrm{~T}$ was associated with either AZT/3TC or ABC/ $\mathrm{TDF}$, no significant decrease in mtDNA to nDNA ratio was observed (Table 2). When the treatments were considered altogether, the mtDNA to nDNA ratio was lower in patients receiving HAART for longer than 5 years than in control patients $(P<0.05)$.

No difference was observed in the mtDNA to nDNA ratio between patients who had received protease inhibitors and those who had not (respectively $0.11 \pm 0.07$ and $0.09 \pm 0.06$ ).

Table 2 Current treatment at time of mtDNA blood levels evaluation

\begin{tabular}{|c|c|c|c|c|c|c|c|}
\hline Current treatment & $\begin{array}{c}\text { Number of } \\
\text { patients }\end{array}$ & Sex $F / M$ & $\begin{array}{c}\text { Age } \\
\text { (mean } \pm \text { s.d. } \\
\text { years) }\end{array}$ & $\begin{array}{c}\text { CD4-count } \\
\text { (mean } \pm \text { s.d. } \\
\text { number/ } \\
\mathrm{mm}^{3} \text { ) }\end{array}$ & $\begin{array}{c}\text { Duration of } \\
\text { the current } \\
\text { treatment } \\
\text { (mean } \pm \text { s.d. } \\
\text { months) }\end{array}$ & $\begin{array}{c}\text { Cumulative } \\
\text { duration of } \\
\text { treatment } \\
\text { (mean } \pm \text { s.d. } \\
\text { months) }\end{array}$ & $\begin{array}{c}\text { Ratio mtDNA/ } \\
\beta \text {-actin } \\
\text { (mean } \pm \text { s.d.) }\end{array}$ \\
\hline $\mathrm{AZT}+3 \mathrm{TC}$ & 31 & $4 / 27$ & $46.4 \pm 8.9$ & $460 \pm 342$ & $17.5 \pm 16.9$ & $24.6 \pm 18.1$ & $0.12 \pm 0.11$ \\
\hline $\mathrm{AZT}+3 \mathrm{TC}+\mathrm{ABC}+\mathrm{TDF}$ & 16 & $3 / 13$ & $41.7 \pm 9.3$ & $332 \pm 210$ & $10.1 \pm 9.0$ & $11.6 \pm 6.2$ & $0.09 \pm 0.05$ \\
\hline $\mathrm{DDI}+\mathrm{D} 4 \mathrm{~T}$ & 12 & $1 / 11$ & $44.2 \pm 7.0$ & $388 \pm 203$ & $19.0 \pm 10.2$ & $65.0 \pm 45.2$ & $0.08 \pm 0.04$ \\
\hline $\mathrm{DDI}+\mathrm{D} 4 \mathrm{~T}+\mathrm{AZT}+3 \mathrm{TC}$ & 42 & $11 / 31$ & $44.0 \pm 9.8$ & $485 \pm 248$ & $23.2 \pm 17.3$ & $33.2 \pm 21.0$ & $0.10 \pm 0.09$ \\
\hline DDI+D4T+ABC+TDF & 10 & $3 / 7$ & $46.9 \pm 10.5$ & $303 \pm 197$ & $12.7 \pm 8.6$ & $28.4 \pm 20.5$ & $0.15 \pm 0.11$ \\
\hline Other treatments & 33 & $7 / 26$ & $43.2 \pm 9.6$ & $320 \pm 213$ & $17.4 \pm 17.1$ & $68.3 \pm 52.8$ & $0.13 \pm 0.12$ \\
\hline
\end{tabular}

There are classified into six groups according to the combination of drugs. The duration of treatment in each group was not significantly different. The mtDNA to nDNA ratio was lower in patients receiving DDI+D4T than in patients receiving AZT $+3 T C(P<0.05)$. AZT $=$ zidovudine, 3TC $=$ lamivudine, $\mathrm{ABC}=$ abacavir, $\mathrm{TDF}=$ tenofovir, $\mathrm{DDI}=$ didanosine and $\mathrm{D} 4 \mathrm{~T}=$ stavudine. 


\section{Discussion}

It is difficult to diagnose mitochondrial toxicity and no metabolic or serological diagnostic assays are currently able to predict which patients will be affected. However, most patients treated with NRTI do not develop mitochondrial toxicity or only have mild and/or long-term toxicity that is more difficult to evaluate during regular follow-up. Thus, we chose to assess out-patients, to mimic the basic situation of the physician faced with patients who exhibit moderate side effects compared to during their previous visit.

Acute lactate acidosis, the most dramatic presentation of mitochondrial toxicity, which is unfortunately fatal in most cases, is rare with about 1.3 cases per 1000 person-years of nucleoside exposure. ${ }^{13,17}$ We observed the same incidence in our cohort of 1000 patients, but none of the patients in our series had an episode of lactic acidosis during the evaluation period (bicarbonate levels were above $22 \mathrm{mmol} / \mathrm{l}$ and lactate levels were below $5 \mathrm{mmol} / \mathrm{l}$ for all the patients). One patient had a severe episode of lactic acidosis 1 year before the study period, but the acid-base equilibrium was normal at the time of evaluation and this patient's mtDNA to nDNA ratio was $32 \%$ of the mean control value.

In our study, the mtDNA to nDNA ratios were lower in the HIV patients than in controls. However, this difference was observed both in naive patients and in HAART-treated patients. The decrease in the mtDNA to nDNA ratios in untreated HIV-1 patients are in agreement with those reported by Cote et $a l^{18}$ and Montaner et $a l^{19}$ but not with those of Petit et al. ${ }^{25}$ The decrease in mtDNA to nDNA ratio in the HIV patients suggests a direct mitochondrial toxicity of the virus. These observations are supported by in vitro studies in which HIV-infected cells showed signs of mitochondrial necrosis. ${ }^{26}$ A mitochondrioncontrolled mechanism of cell death may occur in HIV infection. ${ }^{27-29}$ The lack of a significant difference in the mtDNA to nDNA ratio between HIVnontreated and HIV-treated patients may be due to the absence of acute mitochondrial toxicity in our cohort of patients. Similar results have previously been shown in two studies in which the authors failed to demonstrate mtDNA depletion in asymptomatic patients on different HAART schedules compared with HIV-negative patients. ${ }^{21,22}$ Thus, we can also hypothesize, as the latter authors, that mitochondrial toxicity can lead to a decrease in mitochondrial DNA content in the tissue concerned by the toxicity (ie liver or skeletal muscle) and not in peripheral leukocytes. This conclusion can be compared to a case report of one patient with fatal lactic acidosis; the mitochondrial DNA content in the liver of this patient was found to be abnormally low. ${ }^{10}$

We found that $10 \%$ of untreated HIV-1 patients and $45 \%$ of HAART-treated patients had lipodystrophy syndrome, as previously described. ${ }^{30}$ These values are in agreement with previous findings, showing that about $50 \%$ of patients had at least one physical abnormality characteristic of lipodystrophy after 12-18 months of treatment. ${ }^{31-34}$ Moreover, the frequency of the lipodystrophy syndrome increased with the duration of antiretroviral treatment. However, the value of mtDNA to nDNA ratio was not correlated with the presence of fat redistribution. This may be due to the fact that the mtDNA concentration is already decreased in the mononuclear cells of patients that have never received any antiviral treatment. Only triglyceride levels were significantly higher in treated HIV patients than in naive HIV patients as recently shown by Belloso et $a l^{35}$

Stavudine and didanosine are the two drugs that have most frequently been reported to be associated with hyperlactataemia and thus mitochondrial toxicity. ${ }^{13,36-39}$ This finding is in agreement with in vitro studies demonstrating that these two drugs have a high capacity to inhibit gamma polymerase ${ }^{40}$ and that the triphosphorylated form of stavudine is incorporated into replicating DNA more readily than other NRTIs. ${ }^{41,42}$ We also found that patients treated with stavudine had lower mtDNA to nDNA ratios than those who had never received this drug. However, this difference can be observed in a cohort of patients treated for a long period with HAART but not between two routine visits.

In conclusion, although mtDNA depletion has recently been proposed to be a marker of clinically evident mitochondria-related adverse effects, it can probably not be used as a routine marker to predict who will develop mitochondrial toxicity in a cohort of patients with moderate side effects.

\section{Duality of interest}

None declared.

\section{References}

1 Carr A, Samaras K, Chisholm DJ, et al. Pathogenesis of HIV-1-protease inhibitor-associated peripheral lipodystrophy, hyperlipidaemia, and insulin resistance. Lancet 1998;351:1881-1883.

2 Flexner C. HIV-protease inhibitors. N Engl J Med 1998;338:1281-1292.

3 Riddle TM, Kuhel DG, Woollett LA, et al. HIV protease inhibitor induces fatty acid and sterol biosynthesis in liver and adipose tissues due to the accumulation of activated sterol regulatory element-binding proteins in the nucleus. J Biol Chem 2001;276:37514-37519.

4 Salmon-Ceron D, Chauvelot-Moachon L, Abad S, et al. Mitochondrial toxic effects and ribavirin. Lancet 2001;357:1803-1804.

5 Brinkman K, Smeitink JA, Romijn JA, et al. Mitochondrial toxicity induced by nucleoside-analogue reverse-transcriptase inhibitors is a key factor in the pathogenesis of antiretroviral-therapy-related lipodystrophy. Lancet 1999;354:1112-1115. 
6 Carr A, Miller J, Law M, Cooper DA. A syndrome of lipoatrophy, lactic acidaemia and liver dysfunction associated with HIV nucleoside analogue therapy: contribution to protease inhibitor-related lipodystrophy syndrome. AIDS 2000;14:F25-F32.

7 Masini A, Scótti C, Calligaro A, et al. Zidovudineinduced experimental myopathy: dual mechanism of mitochondrial damage. J Neurol Sci 1999;166:131-140.

8 Morris AA, Carr A. HIV nucleoside analogues: new adverse effects on mitochondria? Lancet 1999;354: 1046-1047.

9 Olano JP, Borucki MJ, Wen JW, et al. Massive hepatic steatosis and lactic acidosis in a patient with AIDS who was receiving zidovudine. Clin Infect Dis 1995;4:973-976.

10 Brivet FG, Nion I, Megarbane B, et al. Fatal lactic acidosis and liver steatosis associated with didanosine and stavudine treatment: a respiratory chain dysfunction? J Hepatol 2000;32:364-365.

11 ter Hofstede HJ, de Marie S, Foudraine NA, et al. Clinical features and risk factors of lactic acidosis following long-term antiretroviral therapy: 4 fatal cases. Int J STD AIDS 2000;11:611-616.

12 Chariot P, Drogov I, de Lacroix-Szmania I, et al. Zidovudine-induced mitochondrial disorder with massive liver steatosis, myopathy, lactic acidosis, and mitochondrial DNA depletion. J Hepatol 1999;30:156-160.

13 Lonergan JT, Behling C, Pfander H, et al. Hyperlactatemia and hepatic abnormalities in 10 human immunodeficiency virus-infected patients receiving nucleoside analogue combination regimens. Clin Infect Dis 2000;31:162-166.

14 Boubaker K, Flepp M, Sudre P, et al. Hyperlactatemia and antiretroviral therapy: the Swiss HIV Cohort Study. Clin Infect Dis 2001;33:1931-1937.

15 Brinkman K. Management of hyperlactatemia: no need for routine lactate measurements. AIDS 2001;15:795797.

16 Simon DK, Johns DR. Mitochondrial disorders: clinical and genetic features. Annu Rev Med 1999;50:111-127.

17 Brinkman K. Hyperlactatemia and hepatic steatosis as features of mitochondrial toxicity of nucleoside analogue reverse transcriptase inhibitors. Clin Infect Dis 2000;31:167-169.

18 Cote HC, Bruhhe ZL, Craib KJ, et al. Changes in mitochondrial DNA as a marker of nucleoside toxicity in HIV-infected patients. N Engl J Med 2002;346: 811-820.

19 Montaner JS, Cote HC, Harris M, et al. Mitochondrial toxicity in the era of HAART: evaluating venous lactae and peripheral blood mitochondrial DNA in HIVinfecting patients taking antiretroviral therapy. J Acquir Immune Defic Syndr 2003;34:S85-S90.

20 Walker UA, Setzer B, Venhoff N. Increased long-term mitochondrial toxicity in combinations of nucleoside analogue reverse-transcriptase inhibitors. AIDS 2002; 16:2165-2173.

21 Henry K, Erice A, Balfour Jr HH, et al. Lymphocyte mitochondrial biomarkers in asymptomatic HIV-1infected individuals treated with nucleoside reverse transcriptase inhibitors. AIDS 2002;16:2485-2487.

22 McComsey G, Tan DJ, Lederman M, et al. Analysis of mitochondrial DNA genome in the peripheral blood leukocytes of HIV-infected patients with or without lipoatrophy. AIDS 2002;16:513-518.

23 Gahan ME, Miller F, Lewin SR, et al. Quantification of mitochondrial DNA in peripheral blood mononuclear cells and subcutaneous fat using real-time polymerase chain reaction. J Clin Virol 2001;22:241-247.

24 Ihaka R, Gentleman R. R: a language of data analysis and graphics. J Comput Graph Stat 1996;5: 299-315.

25 Petit C, Mathez D, Barthelmy C, et al. Quantitation of blood lymphocyte mitochondrial dna for the monitoring of antiretroviral drug-induced mitochondrial DNA depletion. J Acquir Immune Deficiency Syndrome 2003;33:461-469.

26 Plymale DR, Tang DS, Comardelle AM, et al. Both necrosis and apoptosis contribute to HIV-1-induced killing of CD4 cells. AIDS 1999;13:1827-1839.

27 Ferri KF, Jacotot E, Blanco J, et al. Mitochondrial control of cell death induced by HIV-1-encoded proteins. Ann NY Acad Sci 2000;926:149-164.

28 Moretti S, Marcellini S, Boschini A, et al. Apoptosis and apoptosis-associated perturbations of peripheral blood lymphocytes during HIV infection:comparison between AIDS patients and asymptomatic long-term non-progressors. Clin Exp Immunol 2000;122: 364-373.

29 Roggero R, Robert-Hebmann V, Harrington S, et al. Binding of human immunodeficiency virus type 1 gp120 to CXCR4 induces mitochondrial transmembrane depolarization and cytochrome $C$-mediated apoptosis independently of Fas signaling. J Virol 2001;7:7637-7650.

30 Mauss S. HIV-associated lipodystrophy syndrome. AIDS 2000;14:S197-S207.

31 Carr A, Samaras K, Thorisdottir A, et al. Diagnosis, prediction, and natural course of HIV-1 proteaseinhibitor-associated lipodystrophy, hyperlipidaemia, and diabetes mellitus: a cohort study. Lancet 1999;353:2093-2099.

32 Mallal S, John M, Moor C, et al. Protease inhibitors and nucleoside analogue reverse transcriptase inhibitors interact to cause subcutaneous fat wasting in patients with HIV infection. 1st International Workshop on Adverse Drug Reactions and Lipodystrophy, San Diego [abstract 026]. Antiviral Ther 1999;4:42.

33 Mallal SA, John M, Moore CB, et al. Contribution of nucleoside analogue reverse transcriptase inhibitors to subcutaneous fat wasting in patients with HIV infection. AIDS 2000;14:1309-1316.

34 Viard JP, Rakotoambininia B. Lipodystrophic syndromes in a cohort of HIV-1-infected patients receiving HAART with a proteas inhibitor. 1st International Workshop on Adverse Drug Reactions and Lipodystrophy, San Diego, 1999 [abstract 026]. Antiviral Ther 1999;4:47.

35 Belloso WH, Quiros RE, Ivalo SA, et al. Agreement analysis of variables involved in lipodystrophy syndrome definition in HIV-infected patients. J Acquir Immune Deficiency Syndrome 2003;32:104-111.

36 Bonnet F, Bonarek M, Abrij A, et al. Metabolic acidosis in HIV-infected patients. Clin Infect Dis 2002;34: 1289-1290.

37 Delgado J, Harris M, Tesiorowski A, et al. Symptomatic elevations of lactic acid and their response to treatment manipulation in human immunodeficiency virus-infected persons: a case series. Clin Infect Dis 2001;33:2072-2074.

38 Gerard Y, Maulin L, Yazdanpanah Y, et al. Symptomatic hyperlactataemia: an emerging complication of antiretroviral therapy. AIDS 2000;14:2723-2730. 
39 John M, Moore CB, James IR, et al. Chronic hyperlactatemia in HIV-infected patients taking antiretroviral therapy. AIDS 2001;15:717-723.

40 Birkus G, Hajek M, Kramata P, et al. Tenofovir diphosphate is a poor substrate and a weak inhibitor of rat DNA polymerases alpha, delta, and epsilon. Antimicrob Agents Chemother 2002;46:1610-1613.
41 Kakuda TN. Pharmacology of nucleoside and nucleotide reverse transcriptase inhibitor-induced mitochondrial toxicity. Clin Ther 2000;22:685-708.

$42 \mathrm{Lim}$ SE, Copeland WC. Differential incorporation and removal of antiviral deoxynucleotides by human DNA polymerase gamma. J Biol Chem 2001;276: 23616-23623. 